\title{
Endometrial Injury and Sub Endometrial Doppler Study to Predict Uterine Receptivity in Women with Unexplained Infertility: A Randomized Controlled Trial
}

\author{
Manal A. Farahat, Mona Omar \\ Obstetrics \& Gynecology Department, Faculty of Medicine, Tanta University, Tanta, Egypt \\ Email: momar14101976@gmail.com
}

How to cite this paper: Farahat, M.A. and Omar, M. (2019) Endometrial Injury and Sub Endometrial Doppler Study to Predict Uterine Receptivity in Women with Unexplained Infertility: A Randomized Controlled Trial. Open Journal of Obstetrics and Gynecology, 9, 867-877.

https://doi.org/10.4236/ojog.2019.96084

Received: May 19, 2019

Accepted: June 18, 2019

Published: June 21, 2019

Copyright $\odot 2019$ by author(s) and Scientific Research Publishing Inc. This work is licensed under the Creative Commons Attribution International License (CC BY 4.0). http://creativecommons.org/licenses/by/4.0/

\section{Open Access}

\begin{abstract}
Objectives: The aim of this work was to compare the effectiveness and safety of endometrial scratching at different times of the menstrual cycle on cumulative pregnancy rate and also to assess and clarify its relationship and effect on sub-endometrial vasculature blood flow by Doppler ultrasound, in cases of unexplained infertility attempting to conceive spontaneously (without ovulation induction). Study Design: A prospective randomized clinical control study. Patients and Methods: A total of 252 eligible participants were included in the study and randomly allocated using block randomization into three groups: Group A $(\mathrm{n}=84)$ : endometrial scratching was performed during the pre-ovulatory days and Group B $(n=84)$ : endometrial scratching has been done at day 7 of the cycle. Group C (control group): includes 84 cases without endometrial scratching. The Doppler ultrasound will be done. The pulsatility index (PI) and resistance index (RI) of endometrial and sub endometrial arteries were calculated. All women were followed up to 3 months. Results: Cumulative pregnancy rate is $21.42 \%$ and $28.57 \%$ in the study groups A and B respectively which is higher than group $\mathrm{C}$ (control group) (4.76\%) but with statistically insignificant $\mathrm{P}$-value $=0.254$. There is statistically significant difference in RI \& PI between the studied groups and the control group on day 13 ( $\mathrm{P}$ value $<0.001$ ). There is statistically significant difference in PI between day 13 and day 6 for the same group in both groups $(\mathrm{A} \& \mathrm{~B})(\mathrm{P}$ value $<0.003)$, while there is no statistically significant difference in Group C $(\mathrm{P}$ value $=0.156)$. Conclusion: Endometrial scratching is a cost-effective and easy technique which may improve clinical pregnancy rates and endometrial blood flow in women with unexplained infertility.
\end{abstract}




\section{Keywords}

Endometrial Injury, Doppler, Unexplained Infertility, Pregnancy Rate

\section{Introduction}

Infertility is the inability to achieve a pregnancy after 12 months of unprotected intercourse [1].

In the absence of a definable cause for a couple's to achieve pregnancy, unexplained infertility can be diagnosed; the prevalence is about $15 \%-30 \%$ and diagnosed by exclusion [2].

Early embryo abnormalities or implantation failure are the main possible causes of unexplained infertility, which explain loss of about $75 \%$ of pregnancies immediately after conception [2].

Deregulation in different factors and signaling molecules such as prostaglandins, cytokines, integrins, and leukemia inhibitory factor leads to poor endometrial receptivity and repeated implantation failure [3].

Aiming to improve success, different modifications and adjuvants to IVF are given to these patients in spite of lack of data to support their effectiveness; endometrial scratching is one of these techniques which has evidence of higher live-birth rates [4].

Endometrial scratching is a simple, low-cost procedure, corrects asynchrony between endometrium and the conceptus and also promotes purposeful disruption of the endometrium resulting in wound healing by inducing a significant increase in the local secretion of pro-inflammatory cytokines such as macrophage inflammatory protein-1E, tumor necrosis factor- $\alpha$, osteopontin, interleukins, growth factors, and dendritic cells which in turn promotes successful implantation [5].

Uterine and spiral artery perfusion has been found to be markedly improved mainly at the implantation window, so endometrial receptivity is increased [6]. Several studies have shown that uterine receptivity is decreased when the uterine artery impedance has been increased during the mid-luteal phase [7].

Trans-vaginal Doppler pulsed ultrasound became an absolute necessity and an important tool for examining the female reproductive system as it is a non-invasive procedure to assess the uterine perfusion [8].

\section{Materials and Methods}

Women who diagnosed as primary or secondary unexplained infertility (as regard past history of pregnancy) attempting to conceive spontaneously were included in our study through a period from February 2017 till February 2018. All patients were counseled thoroughly about the procedure including its value, hazards and the aim of the study.

A written informed consent was obtained from all participants in the study and ethical approval was obtained from the Faculty's Ethics Committee Each partici- 
pant was given a code number to facilitate registration and to keep privacy of all patients, a file having the same number were made to collect all data about the participant and results of investigations done throughout the period of research.

Inclusion criteria Participant Age 20 - 38 years, Body mass index (BMI) 19 - 25 $\mathrm{kg} / \mathrm{m}^{2}$ and Unexplained infertility diagnosed by normal seminal parameters, patent tubes at HSG, ovulatory by ovulation testing with normal hormonal profile,

Exclusion criteria women with known pelvic inflammatory disease, acute vaginal and/or cervical infection, smokers, endometrial thickness $<8 \mathrm{~mm}$, previous caesarean section with niche development, or women had received any interventions for treatment of their infertility during the three last months, immunologic problems and thrombophilia's, metabolic or endocrine disorders (abnormal thyroid or prolactin levels), any systemic disease, previous endometrial scratching and un-explained uterine bleeding.

Participants fulfilled the inclusion criteria were enrolled in the study and subjected to a detailed history and thorough clinical examination. A total of 252 eligible participants were included in the study and randomly allocated using block randomization into three groups, Patients were blinded for their allocation. Eighty-four participants were included in each group.

Group A and B (interventional groups) $\mathrm{n}=84$ in each group. This intervention was performed in an outpatient setting, after explaining the procedure to the patient. In each group endometrial scratching has been undergone in the posterior wall of the uterus using Rocket endometrial sampling syringe, but at different days of the follicular phase.

Group (A): Endometrial scratching: was performed during the pre-ovulatory days (the day of detecting urinary LH-surge).

Serial trans-vaginal ultrasound scanning for folliculometry from day 8 of cycle onward till the mean diameter of the dominant follicle reaching $17-18 \mathrm{~mm}$ Then, an available commercial kit was used in order to find the spontaneous urinary LH surge after which the endometrial scratching was done,

Group (B): Endometrial scratching has been done at day 7 of the cycle.

All procedures were performed by the same physician.

NB. All women in both interventional groups received paracetamol tablets $1000 \mathrm{mg}$ before the procedure;

No antibiotics were used after the procedure.

Group C (control group): Includes 84 cases without endometrial scratching.

Procedure (1):

The patient was put in lithotomy position under strict asepsis, the cervix had been exposed by a Casco speculum, cleaning the vagina and cervix was done by sterile saline, anterior lip of cervix was held with Allis forceps, then the disposable thin flexible plastic tube, $3 \mathrm{~mm}$ wide, called a pipelle catheter (manufactured by ROCKET MEDICAL PLC) was introduced through the cervix up to the uterine cavity till just resistance felt, then drawn back $1.5 \mathrm{~cm}$ below the fundus, the piston was drawn back to the end of the sheath to create a negative pressure, the sheath was rotated 360 degrees and moved back and forth between the fundus 
and internal os for three times through 30 seconds before extraction.

All participants recruited underwent baseline ultrasonography (USG) on day 6 to evaluate Doppler study of the sub endometrial blood flow, and also, 2 days after LH surge

Procedure (2):

The Doppler ultrasound will be done after asking the patient to empty her bladder and lie in lithotomy position to do trans-vaginal ultrasound by using frequency $9 \mathrm{MHz}$ probe on apparatus Toshiba (APPLIO) the adjacent sub-endometrial regions within $10 \mathrm{~mm}$ of the echogenic endometrial borders. Producing flow and wave from endometrium and sub endometrial arterial and venous supply. The pulsatility index (PI) and resistance index (RI) of sub endometrial arteries were calculated electronically when three similar, consecutive waveforms of good quality were obtained. These parameters express the resistance to flow from the point of measurement downstream.

Both interventional groups performed an endometrial scratch once before starting to practice a regular timed sexual intercourse during ovulation days, at least three times per week, for 3 successive months. All women were followed up to 3 months and none of them received any fertility treatment during the follow up time.

\section{Study outcome:}

The primary outcome was to compare the cumulative pregnancy rate in the two interventional groups, early follicular phases (D7) and late follicular phases (pre-ovulatory).

The second aim was to evaluate the effect of endometrial scratching on sub endometrial blood flow by Doppler ultrasound.

Pregnancy was confirmed by beta human chorionic gonadotropin (hCG) in urine/serum three days after a missed period. If participant conceived, ultrasound examination was performed 10 - 14 days later to confirm intrauterine pregnancy then she was followed till the end of the first trimester of pregnancy. Those with negative pregnancy test were allowed to try for spontaneous conception for another two cycles without any intervention in all groups.

All couples were followed up for three cycles.

Those who conceived were excluded from the next analysis, and were included in the final analysis at the end of 3 months.

No drugs other than those mentioned in the protocol were given to the patient. Any adverse reaction to the procedure was noted. A record of dropouts including premature terminations from the study was maintained.

\section{Statistics}

Statistical presentation and analysis of the present study was conducted, using the mean, standard deviation and chi-square test by SPSS V.16. The calculated " $t$ " was compared with tabulated one at different levels of significance at the degree of freedom $(D F): s D F=(D+n 2)-2$. Chi-square; used if the row and column variables are independent, without indicating strength or direction of the 
relationship. Pearson chi-square and likelihood-ratio chi-square. Fisher's exact test and Yates' corrected chi-square are computed for $2 \times 2$ tables. Chi-square test: For comparison between two groups as regards qualitative data. Fisher's exact test and Monte Carlo test It is used whenever the expected frequency in any of the cells of 2 table falls below 5. This test involves the calculation of the $\mathrm{P}$ value directly, without the use of particular test statistic Linear Correlation Coefficient $[r]$ :

$$
\begin{gathered}
x-x^{2} y-y^{2} \\
X-X y-y r
\end{gathered}
$$

where

$$
\begin{aligned}
& X=\text { Independent variable } . \\
& Y=\text { Dependent variable. }
\end{aligned}
$$

\section{Results}

The results of the present study are demonstrated in Tables 1-5.

Table 1 shows no statistically significant difference between the studied two groups and the control patients as regard age and BMI, Infertility Duration, Basal (FSH), Basal E2, AMH and Day (6) endometrial thickness.

Table 2 shows statistically insignificant difference between the studied and control patients as regard type of the infertility. $\mathrm{P}$ value $=0.052$.

Table 3 shows high incidence in cumulative clinical pregnancy rate $(21.42 \%$ and $28.57 \%$ ) in the study groups A and B respectively comparing to the control

\begin{tabular}{|c|c|c|c|c|c|}
\hline & & Group (A) Study & Group (B) Study & Group (C) & P Volu \\
\hline & & $\mathrm{N}(84)$ & $\mathrm{N}(84)$ & Control N (84) & $P$ value \\
\hline Age & Range & $23-35$ & $25-30$ & $24-38$ & 0100 \\
\hline (Years) & Mean \pm SD & $28.5 \pm 5.2$ & $28.82 \pm 5.29$ & $28.22 \pm 5.31$ & 0.120 \\
\hline $\mathrm{R} M U\left(\mathrm{~V}_{\mathrm{O}} / \mathrm{M}^{2}\right)$ & Range & $19-25$ & $20-23$ & $21.7-22$ & 0250 \\
\hline & Mean \pm SD & $22.5 \pm 1.88$ & $22.18 \pm 2.01$ & $22.1 \pm 2.6$ & \\
\hline Infertility & Range & $2-10$ & $3-6$ & $2-6$ & \\
\hline $\begin{array}{c}\text { Duration } \\
\text { (Years) }\end{array}$ & Mean \pm SD & $3.92 \pm 2.03$ & $3.2 \pm 1.19$ & $5.1 \pm 3.6$ & 0.496 \\
\hline Basal (FSH) & Range & $4.23-9.1$ & $5.5-7.8$ & $3.1-7.3$ & 0.563 \\
\hline$(\mathrm{m} \mathrm{IU} / \mathrm{ml})$ & Mean \pm SD & $4.92 \pm 3.16$ & $6.11 \pm 3.15$ & $5.36 \pm 3.02$ & \\
\hline Basal $E_{2}$ & Range & $28-106$ & $31-85$ & $67-91$ & 0.554 \\
\hline$(\mathrm{pmol} / \mathrm{L})$ & Mean \pm SD & $97.0 \pm 40.2$ & $72.3 \pm 27.7$ & $82.0 \pm 36.7$ & 0.007 \\
\hline $\mathrm{AMH}$ & Range & O.7 - 2.4 & $1.9-2.5$ & $1.1-2.4$ & 0254 \\
\hline $\mathrm{ng} / \mathrm{ml}$ & Mean \pm SD & $1.5 \pm 0.3$ & $1.2 \pm 0.6$ & $1.2 \pm 0.8$ & \\
\hline Day (6) E. thick & Range & $10.4-11.5$ & $10.2-11$ & $9.8-10.5$ & 0178 \\
\hline$(\mathrm{mm})$ & Mean \pm SD & $10.91 \pm 1.85$ & $10.71 \pm 1.70$ & $10.08 \pm 2.35$ & 0.170 \\
\hline
\end{tabular}
group (4.76\%), but statistically insignificant $\mathrm{P}$-value $=0.254$.

Table 1. Age and body mass index (BMI) distribution, Infertility Duration, Basal (FSH), Basal E2, AMH and Day (6) endometria thickness of the studied women. 
Table 2. The percentage of infertility type in the studied groups.

\begin{tabular}{|c|c|c|c|c|c|c|}
\hline \multicolumn{3}{|c|}{ Infertility type } & G (A) & G (B) & $\mathrm{G}(\mathrm{C})$ & Total \\
\hline & & $\mathrm{N}$ & 46 & 65 & 24 & 135 \\
\hline (no previo & regnancy) & $\%$ & $55 \%$ & $77 \%$ & $29 \%$ & $54 \%$ \\
\hline $\mathrm{Sec}$ & & $\mathrm{N}$ & 38 & 19 & 60 & 117 \\
\hline (Previous & egnancy) & $\%$ & $45 \%$ & $23 \%$ & $71 \%$ & $46 \%$ \\
\hline \multirow{2}{*}{\multicolumn{2}{|c|}{ Total }} & $\mathrm{N}$ & 84 & 84 & 84 & 252 \\
\hline & & $\%$ & $100 \%$ & $100 \%$ & $100 \%$ & $100 \%$ \\
\hline \multirow{2}{*}{ Chi-squar } & $\mathrm{X}^{2}$ & & & 3.774 & & \\
\hline & $P$ value & & & 0.052 & & \\
\hline
\end{tabular}

Table 3. Cumulative clinical pregnancy rate of the studied women.

\begin{tabular}{|c|c|c|c|c|c|}
\hline \multicolumn{3}{|c|}{ Clinical pregnancy } & \multirow{2}{*}{$\begin{array}{c}\text { Group (A) } \\
84\end{array}$} & \multirow{2}{*}{$\begin{array}{c}\text { Group (B) } \\
84\end{array}$} & \multirow{2}{*}{$\begin{array}{c}\text { Control group } \\
84\end{array}$} \\
\hline & & Allocated & & & \\
\hline \multirow{3}{*}{\multicolumn{2}{|c|}{ Cycle 1}} & Conceived & $5(5.95 \%)$ & $16(19.4 \%)$ & $2(2.38 \%)$ \\
\hline & & Lost & 2 & 3 & 6 \\
\hline & & Allocated & 77 & 65 & 76 \\
\hline \multirow{3}{*}{\multicolumn{2}{|c|}{ Cycle 2}} & Conceived & $10(11.9 \%)$ & $6(7.14 \%)$ & $22(2.38 \%)$ \\
\hline & & Lost & 1 & 2 & 6 \\
\hline & & Allocated & 66 & 57 & 68 \\
\hline \multirow{2}{*}{\multicolumn{2}{|c|}{ Cycle 3}} & Conceived & $3(3.57 \%)$ & $2(2.38 \%)$ & $0(0 \%)$ \\
\hline & & Lost & 0 & 0 & 0 \\
\hline \multirow{2}{*}{\multicolumn{2}{|c|}{ Total }} & Conceived & $18(21.42 \%)$ & $24(28.57 \%)$ & $4(4.76 \%)$ \\
\hline & & Lost & 3 & 5 & 12 \\
\hline Fisher & F & \multicolumn{4}{|c|}{2.269} \\
\hline exact test & $P$ value & \multicolumn{4}{|c|}{0.254} \\
\hline
\end{tabular}

Table 4 shows statistically significant difference in RI \& PI between the studied group (A) and the control group (C) on day 13, also, show statistically significant difference in RI \& PI between the studied group (B) and the control group $(\mathrm{C})$ on day 13 (P value $<0.001$ ).

At the same time there is statistically significant difference in RI between day 13 and day 6 in each group (P value $<0.001)$.

There is statistically significant difference in PI between day 13 and day 6 in both groups $(A \& B)(P$ value $<0.003)$ while there is no statistically significant difference in Group $(C)$ (P value $=0.156)$.

Table 5 shows the difference in PI between pregnant and non-pregnant participants, statistically insignificant $(\mathrm{P}=0.245)$.

The sub-endometrial end diastolic blood flow was present (low PI) in 42 out of 168 in group ( $\mathrm{A}$ and $\mathrm{B}$ ) with (25\%) pregnancy rate. On the other hand the absence or minimal end diastolic blood flow was observed (high PI) in 126 females out of 168 in the same groups (75\%), whom associated with no conception. In spite of that, the difference is statistically insignificant $(\mathrm{P}=0.245)$. 
Table 4. Comparison between the studied groups according to US Doppler.

\begin{tabular}{|c|c|c|c|c|c|c|}
\hline & US Doppler & $\begin{array}{l}\text { Group A } \\
(\mathrm{n}=84)\end{array}$ & $\begin{array}{l}\text { Group B } \\
(\mathrm{n}=84)\end{array}$ & $\begin{array}{l}\text { Group C } \\
(\mathrm{n}=84)\end{array}$ & $\mathrm{U}$ & $\mathrm{p}$ \\
\hline \multirow{9}{*}{ 蛋 } & Day 6 & & & & & \\
\hline & Range & $0.78-0.81$ & $0.77-0.80$ & $0.78-0.81$ & & \\
\hline & Mean \pm SD & $0.80 \pm 0.01$ & $0.80 \pm 0.01$ & $0.80 \pm 0.01$ & 437.50 & 0.822 \\
\hline & Median & 0.80 & 0.79 & 0.80 & & \\
\hline & Day 13 & & & & & \\
\hline & Range & $0.71-0.76$ & $0.70-0.74$ & $0.78-0.80$ & & \\
\hline & Mean \pm SD & $0.73 \pm 0.02$ & $0.72 \pm 0.02$ & $0.79 \pm 0.01$ & $0.00^{*}$ & $<0.001^{\star}$ \\
\hline & Median & 0.73 & 0.70 & 0.80 & & \\
\hline & $\mathrm{p}_{2}$ & $<0.001^{*}$ & $<0.001^{\star}$ & $<0.001^{*}$ & & \\
\hline \multirow{9}{*}{$\bar{a}$} & Day 6 & & & & & \\
\hline & Range & $1.30-1.33$ & $1.30-1.33$ & $1.30-1.33$ & & \\
\hline & Mean \pm SD & $1.32 \pm 0.01$ & $1.32 \pm 0.01$ & $1.32 \pm 0.01$ & 445.0 & 0.937 \\
\hline & Median & 1.32 & 1.32 & 1.32 & & \\
\hline & Day 13 & & & & & \\
\hline & Range & $1.23-1.29$ & $1.22-1.28$ & $1.30-1.34$ & & \\
\hline & Mean \pm SD & $1.26 \pm 0.02$ & $1.25 \pm 0.02$ & $1.32 \pm 0.01$ & $0.00^{*}$ & $<0.001^{\star}$ \\
\hline & Median & 1.26 & 1.25 & 1.32 & & \\
\hline & $\mathrm{p}_{1}$ & $0.003^{*}$ & $0.003^{*}$ & 0.156 & & \\
\hline
\end{tabular}

$\mathrm{U}, \mathrm{p}: \mathrm{U}$ and $\mathrm{p}$ values for Mann Whitney test for comparing between the three groups; $\mathrm{p}_{1}: \mathrm{p}$ values for Wilcoxon signed ranks test for comparing between day 13 and day 6 in each group *: Statistically significant at $\mathrm{p} \leq 0.05$.

Table 5. The averaged sub endometrial PI.

\begin{tabular}{ccccccc}
\hline No. & & & Average & SD & Minimum & Maximum \\
\hline $\begin{array}{c}42 \\
(25 \%)\end{array}$ & Pregnant & Group A & 1.29 & 0.43 & 0.7 & 1.8 \\
& & Group B & 1.27 & 0.33 & 0.7 & 1.7 \\
126 & Non-pregnant & Group A & 2.27 & 0.58 & 1.0 & 3.7 \\
$(75 \%)$ & Group B & 2.25 & 0.57 & 0.9 & 3.3 \\
$\begin{array}{c}\text { Fisher exact } \\
\text { test }\end{array}$ & F & & & 2.158 & & \\
\hline
\end{tabular}

\section{Discussion}

In the current study, the endometrial scratching is associated with pregnancy rates $(21.42 \%)$ and $(28.57 \%)$ in group A and B respectively, which is higher than control group without use of any ovulation inducing drugs.

Endometrial scratching as a simple and cheap procedure has been widely adopted by infertility specialists and used in tens of thousands of women around 
the world [9]. It's been proposed that injury to the lining of the uterus causes an inflammatory response conducive to implantation [4].

Angiogenesis that occurred after endometrial injury is mainly due to recruitment of cytokines, growth factors, and natural killer cells that subsequently provides adequate blood flow to the tissue and prevents embryo rejection [5].

Parsanezhad and his colleges [10] reported clinical pregnancy was significantly higher in studied cases (endometrial scratch) than in the control group (17.5\% and $6.7 \%$, respectively) $(\mathrm{P}=0.027)$ but used empirical superovulation by clomiphene-citrate. These results are lower than our study. This may be explained by; endometrial scratching is more beneficial than empirical ovulatory stimulations in cases of unexplained infertility.

It was observed that the clinical pregnancy rate in group (A) was higher in the second cycle to the endometrial scratching (55.55\%) than at the first (same) cycle (27.77\%), on the other hand, the clinical pregnancy rate in group B was higher in the same cycle of endometrial scratching (66.66\%) than the second cycle (25\%) which may be explained by the fact that the inflammatory reaction and wound healing like mechanism induced by the endometrial scratching need time to be established, Table 3 .

This is observation could also explain the better results of Gibreel A and his coworkers (2), who performed the endometrial scratching in the luteal phase between days 21 and 26, of the preceding cycle, The clinical pregnancy rate was more than triple that of the control group: $25.9 \%$ versus $9.8 \%$ over a six month period compared with $(21.42 \%),(28.57 \%)$ and $(4.76 \%)$ in group (A, B and C) respectively in the current study. Luteal phase induced endometrial injury has been reported to be associated with the highest decidualization in the next cycle. This long-term effect may rely on the fact that monocytes recruited to scratching sites persist for several months [11].

In this study, the pregnancy rate in cycle (3) was lower than cycle (1 and 2). It may be explained by that, endometrial scratching has a transient effect and it may be better to be repeated Narvekar and his coworkers [11] performed a prospective study where endometrial biopsy was done twice, at days $24-25$ of the previous cycle and between days $7-10$ of the following cycle. The pregnancy was higher in the study group than the controls ( $32.7 \%$ versus $13.7 \%, \mathrm{P}=0.01$ ).

Kalma et al. [12] and Gnainsky et al. [13] mentioned that endometrial changes after endometrial injury are maintained for long period, and some times, increased, in subsequent cycles. This may be explained by the persistence of the pro inflammatory cells which is responsible for endometrial regeneration. On the contrary, Karimzade and his coworkers [14] evaluated that, it is very dangerous to perform endometrial injury on the day of oocyte retrieval as it decreases success rate of IVF.

In the current study, at day 6 of the cycle, at Doppler study of the sub-endometrial blood flow there was no statistically significant difference as regards the resistance index and pulsatility index in sub-endometrial blood flow of the interventional groups A and B and control group (C). 
At day 13 of the cycle, there is statistically significant difference in (RI) in the interventional groups A and B in correlation to control group, which explains the higher pregnancy rate in interventional groups, as it may be due to good blood supply in peri-implantation endometrium as it an essential requirement for normal implantation. On the other hand patients with abundant or insufficient endometrial blood flow as in group (C) had a bad outcome, which proved also by Applebaum [15], Dechaud H et al. [16] Panchal and Chaitanya [17], and Apollo-Assisted Reproduction Unit (2012).

The average PI was higher in non-conception than in conception cycles. In our series, no conception was reported when PI was more than 1.29. Tekay et al. [18] reported no pregnancy when the PI was more than 3.

On the contrary, Gannon et al. [19] found that HCG induced a decrease in both endometrial and sub-endometrial vascularization and measured endometrial flow using a laser Doppler technique and observed uterine perfusion to be at its lowest around the time of ovulation. In spite of that the rates of implantation, clinical pregnancy, and live birth in the endometrial injury group were $67 \%, 49 \%$ and $28 \%$, while, in the control group were $30 \%, 23 \%$ and $14 \%$, respectively.

Regarding to the technique of the endometrial scratching, in the present study we used the disposable Rocket endometrial sampling syringe, (pipelle), which is rapid, simple, flexible to facilitate adaptation to normal uterine curvature, thus promoting contact with the wall of uterine cavity, it has internal piston that creates a vacuum for sample collection without any sharp or painful edges. Also, it is cost effective but it is considered as a blind method.

El-Toukhy and his coworkers [20] suggested improved pregnancy rate following outpatient hysteroscopy is better than blind scratching as it has double benefits in doing scratching and if there was any abnormality, it can be treated at the same time, but it is costly and not obvious whether the hysteroscopy itself produces endometrial trauma or whether the distending medium would have an impact [21].

\section{Conclusion}

Endometrial scratching is a reasonable procedure to improve endometrial receptivity in women with unexplained infertility that was most likely due to implantation failure. Also it is simple, easy and cheap effective procedure and is better to be performed in early follicular phase than that in pre-ovulatory period.

\section{Conflicts of Interest}

The authors declare no conflicts of interest regarding the publication of this paper.

\section{References}

[1] Steptoe, P.C. and Edwards, R.G. (1978) Birth after the Re-Implantation of a Human 
Embryo. The Lancet, 2, 366. https://doi.org/10.1016/S0140-6736(78)92957-4

[2] Gibreel, A., Badawy, A., El-Refai, W. and El-Adawi, N. (2013) Endometrial Scratching to Improve Pregnancy Rate in Couples with Unexplained Subfertility: A Randomized Controlled Trial. Journal of Obstetrics and Gynecology Research, 39, 680-684. https://doi.org/10.1111/j.1447-0756.2012.02016.x

[3] Mor, G. and Koga, K. (2008) Macrophages and Pregnancy. Reproductive Sciences, 15, 435-436. https://doi.org/10.1177/1933719108317253

[4] Heneghan, C., Spencer, E.A., Bobrovitz, N., et al. (2016) Lack of Evidence for Interventions Offered in UK Fertility Centers. BMJ, 355, 16295. https://doi.org/10.1136/bmj.i6295

[5] Nastri, C.O., Gibreel, A., RaineFenning, N., Maheshwari, A., Ferriani, R.A., Bhattacharya, S., et al. (2012) Endometrial Injury in Women Undergoing Assisted Reproductive Techniques. Cochrane Database of Systematic Reviews, No. 7, CD009517. https://doi.org/10.1002/14651858.CD009517.pub2

[6] Yılmaz, N., Kılıç, S., Madendağ, Y., Madendağ, İ., Özgün, A., Özakşit, G., et al. (2010) Endometrial Parameters in IVF and IUI Administration on Elderly Women. Turkish Journal of Medical Sciences, 40, 343-348.

[7] Simon, C. and Belilver, J. (2014) Scratshing beneath Systematicrevew and Meta Analysis: The Back Door Foevedence Based Medicine. Human Reproduction, 29, 1918-1921.

[8] Siristatidis, C., Vrachnis, N., Vogiatzi, P., Chrelias, C., Retamar, A.Q., Bettocchi, S., et al. (2014) Potential Pathophysiological Mechanisms of the Beneficial Role of Endometrial Injury in in Vitro Fertilization Outcome. Reproductive Sciences, 21, 955-965. https://doi.org/10.1177/1933719114525270

[9] Lensen, S., Sadler, L. and Farquhar, C. (2016) Endometrial Scratching for Subfertility: Everyone's Doing It. Human Reproduction, 31, 1241-1244. https://doi.org/10.1093/humrep/dew053

[10] Parsanezhad, M.E., et al. (2013) Pregnancy Rate after Endometrial Injury in Couples with Unexplained Infertility: A Randomized Clinical Trial. Iranian Journal of Reproductive Medicine, 11, 869-874.

[11] Narvekar, S.A., Gupta, N., Shetty, N., Kottur, A., Srinivas, M. and Rao, K.A. (2010) Does Local Endometrial Injury in the Non-Transfer Cycle Improve the IVF-ET Outcome in the Subsequent Cycle in Patients with Previous Unsuccessful IVF? A Randomized Controlled Pilot Study. Journal of Human Reproductive Sciences, 3, 15-19. https://doi.org/10.4103/0974-1208.63116

[12] Kalma, Y., Granot, I., Gnainsky, Y., Or, Y., Czernobilsky, B., Dekel, N. and Barash, A. (2009) Endometrial Biopsy-Induced Gene Modulation: First Evidence for the Expression of Bladder-Transmembranal Uroplakin Ib in Human Endometrium. Fertility and Sterility, 91, 1042-1049. https://doi.org/10.1016/j.fertnstert.2008.01.043

[13] Gnainsky, Y., Granot, I., Aldo, P.B., Barash, A., Or, Y., Schechtman, E., Mor, G. and Dekel, N. (2010) Local Injury of the Endometrium Induces an Inflammatory Response That Promotes Successful Implantation. Fertility and Sterility, 94, 2030-2036. https://doi.org/10.1016/j.fertnstert.2010.02.022

[14] Karimzade, M.A., Oskouian, H., Ahmadi, S. and Oskouian, L. (2010) Local Injury to the Endometrium on the Day of Oocyte Retrieval Has a Negative Impact on Implantation in Assisted Reproductive Cycles: A Randomized Controlled Trial. Archives of Gynecology and Obstetrics, 281, 499-503. https://doi.org/10.1007/s00404-009-1166-1

[15] Applebaum, M. (1995) The Uterine Biophysical Profile. Ultrasound in Obstetrics \& 
Gynecology, 5, 67-68. https://doi.org/10.1046/j.1469-0705.1995.05010067.x

[16] Dechaud, H., Bessueille, E., Bousquet, P.J., Reyftmann, L., Hamamah, S. and Hedon, B. (2008) Optimal Timing of Ultrasonographic and Doppler Evaluation of Uterine Receptivity to Implantation. Reproductive BioMedicine Online, 16, 368-375. https://doi.org/10.1016/S1472-6483(10)60598-6

[17] Panchal, S. and Chaitanya, B.N. (2010) Role of 3D and 3D Power Doppler to Assess Endometrial Receptivity in IUI Cycles. International Journal of Infertility and Fetal Medicine, 1, 19-24. https://doi.org/10.5005/jp-journals-10016-1003

[18] Tekay, A., Martikainen, H. and Jouppilas, P. (1996) The Clinical Value of Transvaginal Colour Doppler Ultrasound in Assisted Reproductive Technology Procedures. Human Reproduction, 11, 1589-1591.

https://doi.org/10.1093/oxfordjournals.humrep.a019448

[19] Gannon, B.J., Carati, C.J. and Verco, C.J. (2007) Endometrial Perfusion across the Normal Human Menstrual Cycle Assessed by Laser Doppler Fluxmetry. Human Reproduction, 12, 132-139. https://doi.org/10.1093/humrep/12.1.132

[20] El-Toukhy, T., Sunkara, S.K., Coomarasamy, A., Grace, J. and Khalaf, Y. (2008) Outpatient Hysteroscopy and Subsequent IVF Outcome: A Systematic Review and Meta-Analysis. Reproductive BioMedicine Online, 16, 712-719. https://doi.org/10.1016/S1472-6483(10)60486-5

[21] Lorusso, F., Ceci, O., Bettocchi, S., Lamanna, G., Constantino, A., Serrati, G. and Depalo, R. (2008) Office Hysteroscopy in an in Vitro Fertilization Program. Gynecological Endocrinology, 24, 465-469. https://doi.org/10.1080/09513590802246232 